\title{
Elderly patients in acute medical wards: factors predicting length of stay in hospital
}

\author{
PAMELA A MAGUIRE, IAN C TAYLOR, ROBERT W STOUT
}

\begin{abstract}
A prospective study of 419 patients aged 70 and over admitted to acute medical wards was carried out by medical staff from a geriatric unit. Data, including presenting problem, housing, social support, mental state, continence, and degree of independence before and after admission, were recorded. Of the 419 patients, 143 remained in hospital after 14 days and 65 after 28 days. The major factors associated with prolonged stay in hospital included advanced age, stroke, confusion and falls as reasons for admission to hospital, incontinence, and loss of independence for everyday activities. Social circumstances did not predict length of stay.

Although these factors are interrelated, the most important influence on length of stay was the medical reason for admission. Early contact with the geriatric medical unit in these patients may speed up the recovery or result in more appropriate placement.
\end{abstract}

\section{Introduction}

Current demographic trends predict a continuing increase in the number of old people during the next two decades at least. ${ }^{\prime}$ This will have implications for the hospital services as elderly people are admitted to hospital more often and stay longer than those in younger age groups. ${ }^{2}$ The average length of stay includes the length of stay of some patients who recover quickly and leave hospital without delay and that of a small number of patients who stay in hospital a long time, sometimes referred to as "bed blockers." ${ }^{4}$

The attachment of geriatricians to acute medical wards results in a reduction of the mean length of stay of elderly patients. ${ }^{5}$ Despite an input of "geriatric" skills, such as multidisciplinary assessment, early planning of discharge arrangements, and familiarity with local resources, however, some patients will probably have a prolonged hospital stay. If these patients could be identified soon after admission the appropriate resources could be made available at an early stage to try to speed up their rehabilitation or find an appropriate alternative placement.

To identify those factors that could predict a prolonged length of stay in hospital, a prospective study of consecutive patients aged 70 and over admitted to the general wards of a Belfast teaching hospital was carried out.

Geriatric Medical Unit, Royal Victoria Hospital, Belfast

PAMELA A MAGUIRE, MB, MRCP, senior registrar

IAN C TAYLOR, MD, MRCP, consultant physician

Department of Geriatric Medicine, Queen's University of Belfast, Belfast BT9 7BL

ROBERT W STOUT, MD, FRCP, professor

Correspondence to: Professor Stout.

\section{Patients and methods}

In the Royal Victoria Hospital, Belfast, consultants or senior registrars from the geriatric medical unit make weekly visits to all general medical wards to assess the elderly patients admitted during the previous week. After consultation with the medical and nursing staff, therapists, and social workers recommendations are made about management.

A total of 419 consecutive patients aged 70 and over were admitted during 14 weeks in 1983 . Of these, 350 were included in the study; 305 patients were interviewed during weekly ward rounds and 45 left hospital before they could be interviewed. Information was obtained from the hospital records of these 45 patients, although in some cases it was necessary, with the permission of the patient's general practitioner, to contact the patients or their relatives for further details. Of the remaining 69 patients, 10 left hospital before assessment and were excluded as their records could not be obtained and 59, of whom 29 had been interviewed, died within 14 days of admission and were therefore excluded. The mean time between admission and assessment was 4.6 days.

Data on accommodation, living arrangements, everyday activities before admission, social support, duration of illness before admission, and previous hospital admissions were obtained from the patients or their relatives. Objective data, including age, sex, and the main reason for admission, were recorded.

Mental score was assessed by the visiting geriatrician using the 10 part Abbreviated Mental Test Score. ${ }^{6}$ On a scale of 1-10, a high score indicated good mental function, 7 or less represented notable impairment, and 3 or less severe impairment. The mental state was judged by the medical and nursing staff and continence or otherwise reported by the nurses. Estimation of everyday activities after admission was normally a rough assessment made by the nursing staff and in many cases would not have been tested fully. Those with severe difficulty, however, were referred to the occupational therapists for detailed assessment and treatment.

When information was not available this fact was recorded-for example, mental scores could not be obtained for some patients because of speech difficulties or impaired consciousness. Apart from 14 patients who were transferred to other hospital departments (usually geriatric units) and included with the "still in hospital" group for statistical purposes it was not possible to find out the patient's placement on discharge as this information was not routinely recorded. For most of the $\mathbf{4 5}$ patients who left hospital before they could be interviewed it was possible to find from the records all the above information except the mental score, everyday activities before admission, and whether admitted to hospital in the previous three months. For four of these patients the main reason for admission could not be determined. These 45 patients were compared with the 305 patients who were interviewed in hospital. Basic characteristics such as age and sex did not differ, and this group was therefore combined with the larger group for statistical analysis.

The date of discharge or death was recorded, and from this it could be deduced whether the patient was still in hospital on days 14 and 28. Those who were were compared with those discharged on days 14 and 28 . Reasons for admission were grouped together for statistical analysis because of their small number (see table II). The category "other reason for admission" included poor mobility (in three patients), genitourinary disorder (11), and social problems (seven).

Group comparisons of qualitative data were made by applying a $\chi^{2}$ test. The conventional level of significance $(p<0.05)$ was used for all comparisons. All data processing and analysis were performed on an ICL 2900 computer. 


\section{Results}

Of 419 patients aged 70 and over admitted to acute medical wards, 143 patients were still in hospital after 14 days and 65 patients after 28 days. The factors that predicted length of stay in hospital are summarised below. Eleven patients who died after 14 days and before 28 days were included in the comparisons at 14 days but not at 28 days. Nine patients died in the second month after admission and one in the third month. The total numbers given in each table refer to patients for whom information was available.

Age (table I) - Increasing age was associated with a progressive reduction in the likelihood of early discharge from hospital at both 14 and 28 days. Only half of those aged 80 and over were discharged at 14 days, and a quarter were still in hospital 28 days after admission. This is twice the proportion of those aged 70-79 who were still in hospital after 28 days. Of the 65 patients who were still in hospital after 28 days, $39(60 \%)$ were aged 80 or over. In contrast, $148(42 \%)$ out of the 350 patients aged 70 and over admitted to hospital were in this age group.

TABLE I-Relation between age and discharge

\begin{tabular}{lccc}
\hline \multirow{2}{*}{$\begin{array}{l}\text { Age } \\
\text { years })\end{array}$} & Total & \multicolumn{2}{c}{ No (\%) of patients still in hospital } \\
\cline { 3 - 4 } & 100 & At 14 days & At 28 dayst \\
\hline $70-74$ & 102 & $31(31)$ & $11(11)$ \\
$75-79$ & 87 & $39(38)$ & $15(15)$ \\
$80-84$ & 61 & $39(45)$ & $22(25)$ \\
$85+$ & 350 & $34(56)$ & $17(28)$ \\
\hline Total & & $143(41)$ & $65(19)$ \\
p Value & $<0.02$ & $<0.02$ \\
\hline
\end{tabular}

^Excluding 10 patients discharged before assessment and 59 patients who died within 14 days of admission.

tEleven patients died between 14 and 28 days after admission.

Main reason for admission (table II) - At least half of the patients with confusion, falls, or stroke were still in hospital after 14 days; less than half the patients with confusion or stroke were discharged at 28 days. This contrasts with patients with cardiovascular, chest, gastrointestinal, or "other" disorders, among whom more than half were discharged at 14 days and more than three quarters at 28 days. If stroke and confusion are omitted from the analysis, however, the rates of discharge for the five other reasons for admission do not differ significantly $(\mathrm{p}>0.05)$.

TABLE II-Relation between main reason for admission and discharge

\begin{tabular}{lccc}
\hline & & \multicolumn{2}{c}{ No $(\%)$ of patients still in hospital } \\
\cline { 3 - 4 } $\begin{array}{l}\text { Presenting } \\
\text { complaint }\end{array}$ & Total & At 14 days & At 28 days* \\
\hline Cardiovascular & 83 & $35(42)$ & $7(8)$ \\
Chest disease & 110 & $38(35)$ & $13(12)$ \\
Confusion & 13 & $8(62)$ & $7(54)$ \\
Falls & 14 & $7(50)$ & $6(43)$ \\
Gastrointestinal & 32 & $12(38)$ & $6(19)$ \\
Stroke & 27 & $20(74)$ & $15(56)$ \\
Other & 67 & $21(31)$ & $10(15)$ \\
\hline Total & 346 & $141(41)$ & $64(18)$ \\
p Value & & $<0.01$ & $<0.001$
\end{tabular}

ॠEleven patients died between 14 and 28 days after admission.

Mental score (table III) - Patients with a low mental score had a reduced likelihood of discharge from hospital at both 14 and 28 days. The more subjective assessment of mental state was associated with figures similar to those from formal mental scores. Of 243 patients considered to be alert, 163 $(67 \%)$ were discharged at 14 days and $208(86 \%)$ at 28 days, whereas for the patients assessed as being severely confused corresponding figures were 19 $(39 \%)$ out of 49 and $31(63 \%)$ out of $49(p=0.0001)$.

Continence-Of the 264 patients who were continent, $175(66 \%)$ were discharged by 14 days and $225(85 \%)$ by 28 days. In contrast, only $14(41 \%)$ of the 34 patients with urinary incontinence and $11(32 \%)$ of the 34 with double incontinence were discharged at 14 days $(p<0.001)$; the corresponding values for 28 days were $19(56 \%)$ and $20(59 \%)$, respectively $(\mathrm{p}<0.001)$.

Everyday activities - Loss of independence for everyday activities after admission, as assessed by the nursing staff at the time of the joint ward
TABLE III-Relation between mental score and discharge

\begin{tabular}{lccc}
\hline & & \multicolumn{2}{c}{ No $(\%)$ of patients still in hospital } \\
\cline { 3 - 4 } Mental score & Total & At 14 days & At 28 days \\
\hline $0-3$ & 30 & $21(70)$ & $11(37)$ \\
$4-7$ & 46 & $22(48)$ & $9(20)$ \\
$8-10$ & 187 & $65(35)$ & $24(13)$ \\
\hline Total & 263 & $108(41)$ & $44(17)$ \\
p Value & & $<0.001$ & $<0.01$ \\
\hline
\end{tabular}

$\star$ Eleven patients died between 14 and 28 days after admission

round, was associated with low rates of discharge at 14 and 28 days, particularly in the case of ability to feed. Everyday activities before admission were not so closely related to discharge.

Social support-No measurement of social support was associated with delay in discharge except support provided only by a neighbour, which was associated with delay at 28 days. This might imply frailty combined with insufficient support from other sources.

Others-There was no significant difference between the groups discharged and those still in hospital at either 14 or 28 days with respect to sex; type of accommodation; living arrangements; social support by home help, relative, warden, or others; number of supports; mean length of illness before admission; or other admissions in the past three months.

\section{Discussion}

General medical wards should have a high turnover of patients with short lengths of stay. With the increasing number of old people in the population and the concentration of illness in old age, however, a proportion of general medical beds tend to be "blocked" with elderly patients whose progress is at best slow and who remain in hospital for prolonged periods. 'The geriatric medical unit with its expertise and facilities for rehabilitation and continuing care is a more appropriate place for some of these patients. The exact division of responsibility between general and geriatric medicine, however, has never been clear. Consequently, several arrangements operate in different parts of the country, ranging from an age related specialty of geriatric medicine ${ }^{8}$ to integration between general and geriatric medicine. ${ }^{9}$ An alternative is for members of the geriatric medical unit to spend time on a regular basis in the general medical ward. ${ }^{5}$ In this study we attempted to define some of the groups of patients with whom the geriatric medical unit should become concerned early in their admissions.

The factors predicting prolonged stay were advanced age; stroke, mental confusion, and falls as the main reason for admission; low mental score or mental confusion; incontinence; loss of independence after admission; and support provided only by a neighbour. As stroke, confusion, and falls are causes or indications of severe disability there is a close interaction between diagnoses and measurements of functional ability. From the proportions still in hospital after two or four weeks, however, the main presenting feature on admission was the major reason for prolonged hospital stay. Interestingly, although elderly patients occupying acute hospital beds for a long time are sometimes described as "social problems," in this study no measure of social support was related to prolonged hospital stay. Clearly diagnosis may influence most of the variables, and this would be in keeping with the reports of other workers who have shown that generally diagnosis is more important than social factors in determining the length of hospital stay of the elderly. ${ }^{3+1011}$

Of the three reasons for admission associated with prolonged hospital stay, stroke often led to considerable disability with slow recovery requiring lengthy rehabilitation or a degree of nursing care that cannot be provided outside hospital. Confusion, falls, and incontinence are often presenting symptoms for various illnesses and may be due to multiple disorders. ${ }^{12}$ They impair the ability to maintain independence in the community, as shown by the loss of independence to perform everyday activities. All these factors are related to the diagnosis, often a disorder affecting cerebral function, 
and create rather than result from impaired social circumstances.

In this study we found an association between increasing age and length of stay, but even in the oldest age group-that is, 85 years and over-44 $(72 \%)$ out of 61 patients were discharged at 28 days. Thus age alone does not make a major contribution to prolonged hospital stay, and even when 14 days is taken as the optimum length of stay in general medical wards only half of those aged 80 years and over are placed inappropriately. Nevertheless, the very old patients remaining in hospital occupy a disproportionate number of bed days.

In conclusion, the prolonged stay in hospital of elderly patients is related to medical rather than social factors. Furthermore, contact with members of a geriatric medical unit in such patients results in shorter lengths of hospital stay, ${ }^{5}$ lower mortality, fewer admissions to nursing homes, and an improvement in functional state after discharge from hospital. ${ }^{13}$ Improvements in community social services would have at best a marginal effect on the turnover of elderly patients in general medical wards. A better approach would be to strengthen geriatric services so that all elderly patients identified as likely to require the expertise of the geriatric medical unit may receive this soon after admission.

We thank Mrs Jean Smith-Davidson and her staff for the punch card recording of the data, Dr D Merrett for statistical advice, Miss A Best for careful typing of the manuscript, and the doctors at the Royal Victoria Hospital, Belfast, for their cooperation in this study.

\section{References}

1 Grundy E. Mortality and morbidity among the old. $\mathrm{Br} M e d$ f 1984;288:663-4

2 Andrews K, Brocklehurst JC. The implications of demographic changes on resource allocation f R Coll Physicians Lond 1985;19:109-11.

3 Rubin SG, Davies GH. Bed blocking by elderly patients in general hospital wards. Age Ageing 1975; $4: 142-7$.

4 Seymour DG, Pringle R. Elderly patients in a general surgical unit: do they block beds? BrMed $\mathcal{f}$ 1982;284:1921-3.

5 Burley LE, Currie CT, Smith RG, Williamson J. Contribution from geriatric medicine within acute medical wards. Br Med $\mathcal{F} 1979 ;$ ii: $90-2$.

6 Qureshi KN, Hodkinson HM. Evaluation of a ten-question mental test in the institutionalized elderly. Age Ageing 1974;3:152-7.

7 McArdle C, Wylie JC, Alexander WD. Geriatric patients in an acute medical ward. Br Med $\mathcal{F}$ 1975; iv:568-9.

8 Bagnall WE, Datta SR, Knox J, Horrocks P. Geriatric medicine in Hull: a comprehensive service. BrMed f 1977;ii: 102-4.

9 Evans JG. Integration of geriatric with general medical services in Newcastle. Lancet 1983; 1430-3.

10 Hodkinson HM, Hodkinson I. Death and discharge from a geriatric department. Age Ageing 1980;9:220-8.

11 Hodkinson HM, Hodkinson I. The influence of route of admission on outcome in the geriatric patient. Age Ageing 1980;9:229-34

2 Wilson LA, Lawson IR, Brass W. Multiple disorders in the elderly. Lancet 1962;ii:841-3.

13 Rubenstein LZ, Josephson KR, Wieland GD, English PA, Sayre JA, Kane RL. Effectiveness of geriatric evaluation unit. A randomized clinical trial. $N$ Engl f Med 1984;311:1664-70.

Accepted 30 January 1986)

\title{
Bed blocking in Bromley
}

\author{
JEREMY COID, PETER CROME
}

\begin{abstract}
A point prevalence survey of all acute beds in the Bromley district found that more than one in 10 patients were classified by their doctors as bed blockers (one in five in the medical wards). There were appreciable clinical and demographic differences distinguishing bed blockers from patients whose stay had been prolonged and who were judged as still requiring acute beds. Social and administrative problems also contributed to bed blocking so that further action by geriatricians, psychogeriatricians, and social workers was required to reduce the numbers. A substantial proportion of bed blockers, however, were highly dependent and could be transferred only to long stay wards or nursing homes.
\end{abstract}

Bed blocking seems inevitable in wards that are attempting to cope with the steadily increasing proportion of elderly patients according to traditional models of acute care.

\section{Introduction}

It is important to know the extent of bed blocking and prolonged stay in acute medical and surgical wards. Not only do these factors prevent the use of a bed for its intended purpose but the presence of bed blockers and long stay patients can also have a detrimental effect

Maudsley Hospital, London SE5

JEREMY COID, MPHIL, MRCPSYCH, senior registrar in psychiatry

Department of Geriatric Medicine, George Stamp Unit, Orpington Hospital, Orpington, Kent BR6 9JU

PETER CROME, MD, MRCP, consultant physician and clinical associate professor, University of Saskatchewan, Canada

Correspondence to: Dr Crome. on staff morale. For example, nurses in one acute medical ward complained of having to be constantly vigilant to prevent ambulant demented patients from wandering and getting lost. On another ward so many patients were awaiting transfer to a long stay geriatric bed that the ward sister voiced her intention to resign. The management proposed that some patients be "referred" to beds in other departments, if necessary against the wishes of the consultant responsible. Indeed, this actually occurred when both acute and geriatric wards had to be closed as part of financial cuts. Most staff believed that these problems had not always existed and were getting worse. Anecdotal accounts from neighbouring districts suggested that the problems were no worse in Bromley than elsewhere.

The generally accepted definition of a bed blocker is someone who has been in hospital for more than four weeks and who in the opinion of the medical and nursing staff no longer requires the facilities provided there. ${ }^{1}$ These patients need to be distinguished from long stay patients, who are thought still to need the facilities of an acute medical ward.

This investigation was initiated by one of us (JC) while on rotation as senior registrar in psychiatry to Bromley health district, the major impetus for the study being the demand by staff that "something must be done." The aims of the study were, firstly, to ascertain the extent of bed blocking in Bromley; secondly, to try and elucidate clinical differences between bed blockers and long stay patients; and, finally, to suggest ways to minimise this problem.

\section{Methods}

Background data were first obtained from the South East Thames Regional Health Authority on trends in occupancy of all acute beds in the four Bromley district hospitals with specialties of general medicine and chest diseases, general surgery including urology, and orthopaedics. Data were obtained for the nine years $1975-83$ on patients' age and duration of stay in the form of $(a)$ the annual number of discharges and deaths and $(b)$ units of occupancy in bed days. 